\title{
Mental Health of People in State Quarantine during COVID-19 Situation in Thailand
}

\author{
Sukjai Charoensuk ${ }^{1,2}$, Kanyawee Mokekhaow ${ }^{1,2}$, Duanphen Channarong ${ }^{3} \&$ Chariya Sonpugdee $^{3}$ \\ ${ }^{1}$ Boromarajonani College of Nursing, Chonburi, Thailand \\ ${ }^{2}$ Faculty of Nursing, Praboromarajchanok Insitute, Nonthaburi, Thailand \\ ${ }^{3}$ Center of Mental Health Region 6, Department of Mental Health, Thailand \\ Correspondence: Sukjai Charoensuk, Boromarajonani College of Nursing, Chonburi 69/1 Moo 2 Bansuan \\ sub-district, Muang district Chonburi province 20000, Thailand. Tel: 66-86-155-6862.
}

Received: June 11, 2021 Accepted: July 6, 2021 Online Published: July 23, 2021

doi:10.5539/gjhs.v13n9p1 URL: https://doi.org/10.5539/gjhs.v13n9p1

\begin{abstract}
When the COVID-19 outbreak spread across the globe, Thailand was the first country to report a COVID patient outside of China. We conducted a cross-sectional descriptive study to examine the mental health condition and the risk factors associated with the mental health problems of people in state quarantine. Our study sample included 4,069 people who were in state quarantine in the eastern region of Thailand. We administered a stress assessment test, a depression screening questionnaire, a suicidal risks screening tool and a COVID-19 anxiety screening scale, which were developed by the Department of Mental Health, Thailand. We found that most people in state quarantine reported a moderate level of COVID-19 anxiety, a mild level of stress, and no current risk of suicide. The risk factors associated with stress were female gender $(\mathrm{OR}=2.290, p<0.001,95 \% \mathrm{CI}$ $[1.687,3.109])$ and having chronic diseases $(\mathrm{OR}=2.443, p<0.001,95 \% \mathrm{CI}[1.720,3.470])$. The factor associated with depression was female gender ( $\mathrm{OR}=1.380, p<0.001,95 \% \mathrm{CI}[1.201,1.586])$. The factors associated with risks for suicide were female gender $(\mathrm{OR}=2.059, p<0.001,95 \% \mathrm{CI}[1.553,2.729])$ and having chronic diseases $(\mathrm{OR}=2.128, p<0.001,95 \% \mathrm{CI}[1.510,2.998])$. The factors associated with COVID-19 anxiety were female gender $(\mathrm{OR}=1.469, p<0.001,95 \% \mathrm{CI}[1.294,1.669])$ and having chronic diseases $(\mathrm{OR}=1.329, p$ $=0.011,95 \%$ CI $[1.066,1.657])$. A system to screen for mental health problems and rapid assistance offered to people in state quarantine who are at risk of mental health problems are recommended to reduce the severity of the problems.
\end{abstract}

Keywords: anxiety, COVID- 19, depression, state quarantine, stress, suicidal risk

\section{Introduction}

Due to the situation caused by COVID-19, which began in China then spread worldwide with increasing severity, the WHO declared the COVID-19 outbreak a pandemic (World Health Organization [WHO], 2020). COVID-19 has had tremendous impact on the health and living conditions of people in every region of the world. Thailand was the first country to report COVID patients outside of China on January 13, 2020 (WHO, 2020). The Thai government announced a general state of emergency nationwide on March 26, 2020 (Royal Thai Government Gazette [RTGG], 2020a). Thailand rapidly developed policies and established the Center for COVID-19 Situation Administration (CCSA) to perform duties in accordance with the Emergency Decree on Public Administration in Emergency Situations B.E. 2548. The CCSA launched a public relations campaign to disseminate accurate and factual information and news in order to enhance good understanding between the government and the public (Royal Thai Government Gazette [RTGG], 2020b). The CCSA required people returning from abroad to be quarantined for 14 days at places designated by the government to prevent infected persons and vulnerable persons from spreading the disease to others since April 3, 2020.

Although successful quarantine can prevent the spread of the disease, state quarantine potentially impacted the quarantined persons, especially with regards to their mental health. Quarantine is mostly perceived as an unpleasant experience for people who undergo it. It may cause negative psychological effects, including post-traumatic stress symptoms, confusion and anger (Brooks et al., 2020). A study that was conducted with persons older than 18 years in Wuhan, China during the COVID-19 outbreak and national lockdown measures 
found that $48.3 \%, 22.6 \%$, and $19.4 \%$ of study participants experienced depression, anxiety, and depression together with anxiety, respectively (Gao et al., 2020). In addition, another study was conducted on the factors influencing mental health problems in residents of 31 cities in China, which employed household quarantine measures. According to this study, the most frequently encountered mental health problems were depression and stress. The factors influencing the onset of mental health problems were perceived disease severity and self-control (Li, Yang, Dou, \& Cheung, 2020).

In Thailand, the Department of Mental Health closely followed the people's mental health condition in the ongoing COVID-19 crisis. Nationwide, the reported suicide rate increased from 6.64 per 100,000 population in 2019 to 7.37 per 100,000 population in 2020 (Department of Mental Health Thailand [DMH], 2020 a). According to a nationwide cross-sectional survey in Thailand, depression, anxiety, stress, and insomnia were significant mental health problems found in Thai people during COVID-19 crisis. These mental health problems were correlated with an exposure to COVID-19 information. The participants who exposed to information for 3 or more hours per day had a higher risk of developing symptoms of depression, anxiety, and insomnia than those exposed to information for less than 1 hour per day. (Mongkhon et al., 2021). Stress and depression were significant psychological impacts on healthcare workers during COVID-19 outbreak. Sangsirilak and Sangsirilak (2020) found that a majority of healthcare workers in disease control department and cohort ward reported a moderate level of stress and depression. To our knowledge, no previous study has reported the mental health condition of people in state quarantine in Thailand. The psychosocial and emotional reaction to the COVID-19 pandemic reported in the general population may be different from persons in state quarantine. Therefore, we conducted a cross-sectional descriptive study to examine the mental health condition of persons placed in state quarantine. We explored relationships between mental health problems and personal factors, including age, gender, and having chronic illnesses of persons placed in state quarantine. Results from our study can help design the proper psychosocial intervention to ease mental health problems of people in state quarantine and guide policy makers who create quarantine management plans.

\section{Methods}

\subsection{Study Design and Setting}

The study was a cross-sectional descriptive study. The setting of study was the Health Region 6 of Thailand, which consists of eight provinces in eastern region of Thailand. The government assigned Health Region 6 to set up places to quarantine people from Suvarnabhumi and Utapao airports. During the first wave of COVID-19 outbreak in Thailand (March 26, 2020 to July 8, 2020), all persons returning from aboard were required to quarantine in designated places. The Health Region 6 selected 17 qualified hotels in the area to be places for state quarantines. The criteria for selecting the hotels composed of five dimensions, including building structure, staffing, essential material provision, medical supplies, and environment management. The building structure required a private room with separate air condition system and CCTV (Closed-circuit television) for each person. The staffs required a training course for every person involved. Essential material provision included a computer with free wifi, a flashlight, a kettle, towels, bedsheet, food and drinking water. Medical supplies included alcohol gel, basic medicines, gloves and trash cans. Environment management included a standard waste and water management system, and also making community surrounded understand and accept the hotel's quarantine.

\subsection{Participants}

The participants were 4,082 persons who placed in those 17 hotels designated for state COVID-19 quarantine from 16 April to 30 June 2020. There were 4,069 participants provided written informed consent before participating in the study.

\subsection{Research Instruments}

We administered five questionnaires, which we summarize as follows:

1) A demographic data questionnaire was developed by researchers to assess personal data, covering gender, age, a history of having chronic disease, domicile, and the country in which the quarantined person resided prior to return to Thailand.

2) A stress self-assessment test developed by Silpakit (2008). It consisted of five questions asking the participants to rate their feelings over the past two weeks. The four-rating scale ranged from not at all (0) to most of time (3). The scores were interpreted as follow:

$0-4$ indicated mild stress or regular stress in daily life.

5-7 indicated moderate stress or stress during a crisis or disaster, in which a person needed to make preparations to 
deal with problems. This stress level is still considered normal, and it can cause a person to have enthusiasm in confronting problems.

8-9 indicated severe stress or stress in a crisis or disaster in which temporary severe responses might occur, and this stress normally decreases after the situation has ended.

10-15 indicated the most severe stress or stress so severe that physical symptoms occur, including weakness and vulnerability to illness. This stress also influences the mental state and might lead to anxiety, depression, or risk of suicide. Thus, treatment is required.

The cut-off to indicate a level of stress that need a concern from health care team was five or more. The reliability of this questionnaire examined using Cronbach alpha coefficient was 0.80

3) A depression screening questionnaire developed by Chantakarn, Pukrittayakamee and Saisavoey (2014). It consisted of two questions (2Q) asking the participants to rate their feelings based on "Yes" or "No" options. If "No" was answered for both questions, then the person assessed did not have depression. If "Yes" was answered for either one or both questions, then the person assessed had depression. The psychometric properties of this questionnaire showed a sensitivity of $73 \%$, specificity of $90 \%$, positive predictive value of $59 \%$, negative predictive value of $94 \%$, likelihood ratio of positive result of 7.3 , and likelihood ratio of negative result of 0.3 (Chantakarn et al., 2014).

4) A suicidal risk screening tool developed by the Department of Mental Health (DMH, 2020b). It consisted of eight questions asking the participants check their thoughts and behavior using "Yes" or "No" answers. The score was given differently to each question with a minimum score of 1 and maximum score of 10 . The scores were summed and interpreted as follow:

0 indicated no risk of suicide at the present.

1-8 indicated low risk of suicide at the present.

9-16 indicated moderate risk of suicide at the present.

More than 17 indicated high risk of suicide at the present.

The score of one or more was a cut-off for risk of suicide that health care team should be concern. The reliability of this questionnaire examined using Cronbach alpha coefficient was 0.65

5) A COVID-19 anxiety screening scale developed by the Department of Mental Health (DMH, 2020b). It consisted of five questions asking the participants to rate their feelings over the past two weeks on three rating scale ranging from not at all (1) to most of time (3). The scores were interpreted as follows:

5-6 indicated low anxiety.

$7-11$ indicated moderate anxiety.

$12-15$ indicated high anxiety.

The cut-off to indicate a level of anxiety that need a concern from health care team was seven or more. The reliability of this questionnaire examined using Cronbach alpha coefficient was 0.70 .

\subsection{Ethical Considerations}

We applied for ethical approval on research involving human subjects and the study was approved by the Institutional Review Board on Research Involving Human Subjects of the Baromarajonani College of Nursing, Chonburi, with No. BNC REC 16/2563. We explained the purpose of the study and process of collecting data to participants. We received informed consent from participants who were willing to participate in the study. The participants had a right to refuse and still received care for persons in state quarantine as declared in a protocol.

\subsection{Data Collection}

We combined all five instruments into an online questionnaire using the Google Forms. The online questionnaire was distributed to all participants individually through "LINE" application. The participants could complete the questionnaire at their own convenience starting on day 3 of quarantine. Most of participants $(95.65 \%)$ completed the questionnaire in the day three. The data were collected from April 16, 2020 to June 30, 2020. The researchers verified the correctness and completeness of data after the end of data collection. Next, the data were analyzed.

\subsection{Data Analysis}

We calculated descriptive statistics, including frequencies, percentages, mean and standard deviations, for demographic variables, stress, depression, suicidal risk, and anxiety levels. 
Since we concerned about persons who had mental health problem or not, we categorized participants into two groups for each symptom using its cut-off. We analyzed the relationship between various demographic factors and having stress, depression, suicidal risk, and anxiety using binary logistic regression. The effect estimates were presented as odds ratio along with their corresponding 95\% confidence intervals (CIs).

\section{Results}

\subsection{Demographic Data}

The study population consisted of 4,069 people. Most of the subjects (56.60\%) were female. In addition, $51.2 \%$ of the subjects were 30 years and over with mean age at 32.82 years. Only $9 \%$ of the subjects had chronic diseases, which included allergies, gastritis, hypertension, asthma, and diabetes. The domicile of most subjects was the northeastern region of Thailand (34.79\%), followed by the central region of Thailand (17.91\%) and Bangkok $(17.31 \%)$, respectively. The largest percentages of subjects were returning from Taiwan $(15.73 \%)$, the United States (12.16\%), and Australia (8.09\%), respectively.

\subsection{Mental Health Condition of People in State Quarantine}

The mental health condition in the study was assessed through levels of stress and anxiety related to COVID-19, depressive symptoms, and risks of suicide as shown in Table 1

Table 1. Numbers, Percentages, Means, Standard Deviations, and Level of Mental Health Condition of People (N= $4,069)$ in State Quarantine

\begin{tabular}{|c|c|c|c|c|}
\hline Mental Health Condition & $\mathrm{N}$ & Percentage (\%) & $\begin{array}{l}\text { Mean Score } \\
(\mathrm{SD})\end{array}$ & Interpretation of Mean Score \\
\hline \multicolumn{5}{|l|}{ Stress } \\
\hline Mild Stress & 3169 & 77.9 & \multirow{4}{*}{$2.82(2.61)$} & \multirow{4}{*}{ Mild } \\
\hline Moderate Stress & 669 & 16.4 & & \\
\hline Severe Stress & 131 & 3.2 & & \\
\hline Most Severe Stress & 100 & 2.5 & & \\
\hline \multicolumn{5}{|l|}{ Depression } \\
\hline No & 2885 & 70.9 & & \\
\hline Yes & 1184 & 29.1 & & \\
\hline \multicolumn{5}{|l|}{ Risk of Suicide } \\
\hline No Current Risks & 3810 & 93.6 & \multirow{4}{*}{$0.37(2.17)$} & \multirow{4}{*}{ No risk } \\
\hline Low Risk & 225 & 5.5 & & \\
\hline Moderate Risk & 18 & 0.4 & & \\
\hline High Risk & 16 & 0.4 & & \\
\hline \multicolumn{5}{|c|}{ Coronavirus-Related Anxiety } \\
\hline Low Anxiety & 1619 & 39.8 & \multirow{3}{*}{$7.24(1.81)$} & \multirow{3}{*}{ Moderate } \\
\hline Moderate Anxiety & 2368 & 58.2 & & \\
\hline High Anxiety & 82 & 2.0 & & \\
\hline
\end{tabular}

According to Table 1, most participants (77.9\%) had mild stress with a mean score of 2.82. Although the majority of participants $(70.9 \%)$ reported no depression, we are concerned about the $29.1 \%$ of participants who reported symptoms of depression. The mean suicidal risk score indicated no risks for suicide among participants overall. However, the mean score of coronavirus-related anxiety indicated a moderate level of anxiety among participants.

\subsection{Relationships between Demographic Variables and Mental Health Conditions}

The binary logistic regression was conducted to analyze a probability of having mental health problems, including stress, depression, suicidal risk and anxiety (Table 2). We reported the odd ratio for the probability of having mental health problems (Table 3). 
Table 2. Relationships between Demographic Variables and Mental Health Conditions Using Binary Logistic Regression

\begin{tabular}{|c|c|c|c|c|c|}
\hline Mental Health Outcome/ Demographic variable & $\mathrm{B}$ & S.E & Wald & $\mathrm{EXP}(\mathrm{B})$ & p-value \\
\hline \multicolumn{6}{|l|}{ Stress } \\
\hline Gender & -.828 & .158 & 28.193 & .437 & $<0.001$ \\
\hline Age & -.452 & .140 & 10.442 & .636 & $<0.001$ \\
\hline Having chronic diseases & -.893 & .179 & 24.891 & .409 & $<0.001$ \\
\hline \multicolumn{6}{|l|}{$\mathrm{R}^{2}=.045$, Constant $=-1.550$} \\
\hline \multicolumn{6}{|l|}{ Depression } \\
\hline Gender & -.322 & .071 & 20.619 & .724 & $<0.001$ \\
\hline Age & -.204 & .070 & 8.609 & .815 & $<0.001$ \\
\hline Having chronic diseases & -.133 & .115 & 1.319 & .876 & .251 \\
\hline \multicolumn{6}{|l|}{$\mathrm{R}^{2}=.011$, Constant $=-.538$} \\
\hline \multicolumn{6}{|l|}{ Risk of suicide } \\
\hline Gender & -.722 & .144 & 25.241 & .486 & $<0.001$ \\
\hline Age & -.253 & .131 & 3.740 & .777 & .053 \\
\hline Having chronic diseases & -.755 & .175 & 18.615 & .470 & $<0.001$ \\
\hline \multicolumn{6}{|l|}{$\mathrm{R}^{2}=.032$, Constant $=-1.655$} \\
\hline \multicolumn{6}{|l|}{ Coronavirus-Related Anxiety } \\
\hline Gender & -.385 & .065 & 35.195 & .681 & $<0.001$ \\
\hline Age & -.158 & .065 & 5.967 & .854 & .015 \\
\hline Having chronic diseases & -.285 & .113 & 6.394 & .752 & .011 \\
\hline
\end{tabular}

According to Table 2, being female, older age and having chronic diseases were significant demographic variables that when combined were able to explained $4.5 \%$ of the variance in stress, and $1.6 \%$ of the variance in anxiety. Only being female and older age were significant demographic variables that explained variance of depression at $1.1 \%$. Being female and having chronic diseases were combined to explain $3.2 \%$ of the variance in suicidal risk.

Table 3. Relationship between Demographic Data and Mental Health Condition

\begin{tabular}{|c|c|c|c|c|}
\hline \multirow{2}{*}{ Mental Health/ Demographic data } & \multirow{2}{*}{ OR } & \multicolumn{2}{|c|}{$95 \% \mathrm{CI}$} & \multirow{2}{*}{ p-valuc } \\
\hline & & LL & UL & \\
\hline \multicolumn{5}{|l|}{ Stress } \\
\hline \multicolumn{5}{|l|}{ Gender } \\
\hline Female & 2.290 & 1.687 & 3.109 & 0.000 \\
\hline \multicolumn{5}{|l|}{ Male } \\
\hline \multicolumn{5}{|l|}{ Age } \\
\hline Under 30 Years & 0.636 & 0.484 & 0.837 & 0.001 \\
\hline \multicolumn{5}{|l|}{30 Years \& Up } \\
\hline \multicolumn{5}{|l|}{ Chronic Disease } \\
\hline Yes & 2.443 & 1.720 & 3.470 & 0.000 \\
\hline No & & & & \\
\hline
\end{tabular}




\begin{tabular}{|c|c|c|c|c|}
\hline \multirow{2}{*}{ Mental Health/ Demographic data } & \multirow{2}{*}{ OR } & \multicolumn{2}{|c|}{$95 \% \mathrm{CI}$} & \multirow{2}{*}{ p-value } \\
\hline & & LL & UL & \\
\hline \multicolumn{5}{|l|}{ Depression } \\
\hline \multicolumn{5}{|l|}{ Gender } \\
\hline Female & 1.380 & 1.201 & 1.586 & 0.000 \\
\hline \multicolumn{5}{|l|}{ Male } \\
\hline \multicolumn{5}{|l|}{ Age } \\
\hline Under 30 Years & 0.815 & 0.711 & 0.934 & 0.003 \\
\hline \multicolumn{5}{|l|}{30 Years \& Up } \\
\hline \multicolumn{5}{|l|}{ Chronic Disease } \\
\hline Yes & 1.142 & 0.911 & 1.432 & 0.251 \\
\hline \multicolumn{5}{|l|}{ No } \\
\hline \multicolumn{5}{|l|}{ Risk of Suicide } \\
\hline \multicolumn{5}{|l|}{ Gender } \\
\hline Female & 2.059 & 1.553 & 2.729 & .000 \\
\hline \multicolumn{5}{|l|}{ Male } \\
\hline \multicolumn{5}{|l|}{ Age } \\
\hline Under 30 Years & .777 & .601 & 1.003 & .053 \\
\hline \multicolumn{5}{|l|}{30 Years \& Up } \\
\hline \multicolumn{5}{|l|}{ Chronic Disease } \\
\hline Yes & 2.128 & 1.510 & 2.998 & .000 \\
\hline \multicolumn{5}{|l|}{ No } \\
\hline \multicolumn{5}{|l|}{ Coronavirus-Related Anxiety } \\
\hline \multicolumn{5}{|l|}{ Gender } \\
\hline Female & 1.469 & 1.294 & 1.669 & .000 \\
\hline \multicolumn{5}{|l|}{ Male } \\
\hline \multicolumn{5}{|l|}{ Age } \\
\hline Under 30 Years & .854 & .752 & .969 & .015 \\
\hline \multicolumn{5}{|l|}{30 Years \& Up } \\
\hline \multicolumn{5}{|l|}{ Chronic Disease } \\
\hline Yes & 1.329 & 1.066 & 1.657 & .011 \\
\hline No & & & & \\
\hline
\end{tabular}

Table 3 showed that the likelihood of stress onset depended on gender and presence of chronic disease. In addition, females were more likely to experience greater stress when compared with males $(\mathrm{OR}=2.290, p<.01,95 \% \mathrm{CI}$ $[1.687,3.109])$, and stress was also likely to be higher in the presence of chronic disease when compared with absence of chronic disease $(\mathrm{OR}=2.443 p<.01,95 \% \mathrm{CI}[1.720,3.470])$. Depression depended on gender, by which females were more likely to experience greater depression when compared with males $(\mathrm{OR}=1.380, p<.01$, $95 \% \mathrm{CI}[1.201,1.586])$. Risk of suicide depended on gender and the presence of chronic disease, by which females were more likely to have greater risk of suicide when compared with males $(\mathrm{OR}=2.059 p<.01,95 \% \mathrm{CI}[1.553$, 2.729]), and the presence of chronic disease contributed to greater risk of suicide when compared with no chronic disease $(\mathrm{OR}=2.128 p<.01,95 \% \mathrm{CI}[1.510,2.998])$. COVID-19 anxiety rose with gender and chronic disease, by which the female gender was more likely to have greater anxiety when compared with males $(\mathrm{OR}=1.469, p<.01$, 95\% CI [1.294, 1.669]), and chronic disease contributed to greater likelihood of higher anxiety levels when compared with those having no chronic disease $(\mathrm{OR}=1.329, \mathrm{p}<.05,95 \% \mathrm{CI}[1.066,1.657])$. 


\section{Discussion}

This study examined the mental health condition of persons placed in state quarantine and analyzed the relative risk in the onset of their mental health problems associated with various demographic variables.

\subsection{The Mental Health Conditions}

People in state quarantine in Thailand reported a moderate level of anxiety related to COVID-19, and mild stress. These results contradicted with a systematic review by Salari et al. (2020). In our study, the majority of people reported no depressive symptoms and no risk of suicide, indicating fairly low mental health problems. Studies on psychological impact of quarantine found that inadequate supplies, inadequate information, frustration and boredom, and finances are significant stressors during quarantine (Brook et al., 2020; Pellecchia et al., 2015; Wilken et al., 2017). The Thai government set up a management system that not only for prevented disease, but also protected people in state quarantine. Thai government provided food, accommodation, transportation, and necessary supplies for Thai citizens in state quarantine with no charge. Health information and practice guidelines were provided by health personnel regularly every day. This information included the low mortality rate in the situation of the pandemic in Thailand (1.85\%) and high rate of recovery $(96.2 \%)$, which contributed to low stress, depression, and risk of suicide (DMH, 2020c).

\subsection{Relative Risk in the Onset of the Mental Health Problems}

The study found that the mental health problems of people in state quarantine in Thailand were associated with being female and having chronic diseases. Females in our study were more likely to experience stress, depression, and risk of suicide than males. These results are consistent with studies in China and Iran, which found that females were more likely to experience stress, anxiety and depression from the COVID-19 pandemic than males (Moghanibashi-Mansourieh, 2020; Wang et al., 2021; Zhou et al., 2020). Roongrueangkolkit (2010) addressed the relationship between gender and mental health of Thai people. Roongrueangkolit stated that women usually adapted emotion focused coping patterns, which led to women having more emotional problems than men.

In addition, we also found that people in state quarantine with chronic diseases were more likely to experience stress, depression, risk of suicide, and anxiety than those without chronic diseases. In the COVID-19 pandemic, persons with chronic illness must cope not only with their existing illness, but also with a deadly, invisible, and mysterious virus. Ciacci and Siniscalchi (2020) recommended that the health care providers should provide prompt psychological support in addition to medical assistance for chronically ill patients in the lockdown situation from COVID-19 pandemic.

\subsection{Limitation of the Study}

The study has some limitations that need to be addressed. Since the state quarantine was set up in an emergency situation, we need to rapidly screen these mental health problems using an online survey. The measures used were developed by the Department of Mental Health Thailand based on Thai context, not standardized measures. The mental health problems reported in the study is not a standard medical diagnosis. Only necessary personal characteristics were recorded. Therefore, further study to examine mental health problems of those who reported a high level of stress, a risk of suicide, having depression and anxiety using a standard medical diagnosis should be done.

\section{Conclusion}

The mental health problems of persons placed in state quarantine in Thailand included stress, depression, risk of suicide and anxiety. We found that being female and having chronic illness were associated with greater risk for mental health problems. Anxiety related to COVID-19 was the most problematic issue perceived by people in state quarantine. Therefore, health care providers in the state quarantine must provide psychological support to reduce their anxiety. Although levels of stress and depression were minimal, those who report depressive symptoms need to be assisted. We recommend the presence of a mental health screening system for persons placed in state quarantine to detect persons at risk of mental health problems. We also recommend the development of interventions to decrease the severity of mental health problems during disease outbreaks.

\section{Acknowledgements}

This study was supported by Boromarajonani College of Nursing, Chonburi (BNC). Its contents are solely the responsibility of the authors and do not necessarily represent the official views of the BNC college. We would like to express our gratitude to all participants in this study, and all healthcare team members who assisted in the data collection. 


\section{Competing Interests Statement}

The authors declare that there are no competing or potential conflicts of interest.

\section{References}

Brooks, S. K., Webster, R. K., Smith, L. E., Woodland, L., Wessely, S., Greenberg, N., \& Rubin, G. J. (2020). The psychological impact of quarantine and how to reduce it: rapid review of the, evidence. Lancet, 395, 912-20. https://doi.org/10.1016/S0140-6736(20)30460-8

Chantakarn, S., Pukrittayakamee, P., \& Saisavoey, N. (2014). Accuracy of the two-question screening for depression in psychiatric patients at the consultation liaison unit, Faculty of Medicine Siriraj Hospital, Mahidol University. J Psychiatr Assoc Thailand, 59(10), 51-61.

Ciacci, C., \& Siniscalchi, M. (2020). Tips from the battlefront: Psychological support of patients with a chronic illness during the COVID-19 lockdown in four steps. UEG Journal, 8(6), 741-742. https://doi.org/10.1177/2050640620927564

Department of Mental Health Thailand. (2020a). Coronavirus situation report. Nonthaburi: Ministry of Public Health.

Department of Mental Health Thailand. (2020b). Team operator's manual for mental healing on every level for persons affected by the COVID-19 crisis. Nonthaburi: Ministry of Public Health.

Department of Mental Health. (2020c). Mental health and psychosocial perspectives on the COVID-19 pandemic. Nonthaburi: Ministry of Public Health.

Gao, J., Dai, J., Zheng, P., Chen, H., Mao, Y., Chen, S., ... Jia, Y. (2020). Mental health problems and social media exposure during COVID-19 outbreak. PLoS ONE, 15(4), 0231924. https://doi.org/10.1371/journal.pone.0231924

Li, J. B., Yang, A., Dou, K., \& Cheung, R. (2020). Self-control moderates the association between perceived severity of Coronavirus Disease 2019 (COVID-19) and mental health problems among the Chinese public. International journal of environmental research and public health, 17(13), 4820. https://doi.org/10.3390/ijerph17134820

Moghanibashi-Mansourieh, A. (2020). Assessing the anxiety level of Iranian general population during COVID-19 outbreak. Asian $J$ Psychiatr. PMID: 32334409; PMCID: PMC7165107. https://doi.org/10.1016/j.ajp.2020.102076

Mongkhon, P., Ruengorn, C., Awiphan, R., Thavorn, K., Hutton, B., Wongpakaran, N., ... Nochaiwong, S. (2021). Exposure to COVID-19-related information and its association with mental health problems in Thailand. $J$ Med Internet Res, 23(2), e25363. https://doi.org/10.2196/25363

Pellecchia, U., Crestani, R., Decroo, T., Van den Bergh, R., \& Al-Kourdi, Y. (2015) Social consequences of Ebola containment measures in Liberia. PLoS ONE, $10(12) . \quad$ e0143036. https://doi.org/10.1371/journal.pone.0143036

Roongrueangkolkit, S. (2010). Gender and mental health problems. Journal of the Psychiatric Association of Thailand, 55(1), 109-118.

Royal Thai Government Gazette [RTGG]. (2020a, March 25). Emergency announcement: Government administration during emergencies. Retrieved June 10, 2021 from http://www.nsc.go.th/wp-content/uploads/2020/05/CV19-02.pdf.

Royal Thai Government Gazette [RTGG]. (2020b, March 25). Establishment of a special task force to perform duties in accordance with the emergency decree on public administration in emergency situations B.E. 2548 (2005). Retrieved June 10, 2021 from http://www.nsc.go.th/wp-content/uploads/2020/05/CV19-05.pdf.

Salari, N., Hosseinian-Far, A., Jalali, R., Vaisi-Raygani, A., Rasoulpoor, S., Mohammadi, M., ... Khaledi-Paveh, B. (2020). Prevalence of stress, anxiety, depression among the general population during the COVID-19 pandemic: a systematic review and meta-analysis. Globalization and Health, 16(57), 1-11. https://doi.org/10.1186/s12992-020-00589-w

Sangsirilak, A., \& Sangsirilak, S. (2020). Stress and depressed mood in healthcare workers during COVID-19 outbreak. J Psychiatr Assoc Thailand 65(4), 400-408. Retrieved from http://www.psychiatry.or.th/JOURNAL/65-4/65-4-07_Akekalak.pdf.

Silpakit, O. (2008). Srithanya stress scale. Journal of Mental Health of Thailand, 16(3), 178-185. 
Wang, Y., Di, Y., Ye, J., \& Wei, W. (2021). Study on the public psychological states and its related factors during the outbreak of coronavirus disease 2019 (COVID-19) in some regions of China. Psychol Health Med, 26(1), 13-22. https://doi.org/10.1080/13548506.2020.1746817

Wilken, J. A., Pordell, P., Goode, B., Jarteh, R., Miller, Z., Saygar, B. G., .. \& Yeiah, A. (2017). Knowledge, attitudes, and practices among members of households actively monitored or quarantined to prevent transmission of Ebola Virus Disease Margibi County, Liberia. Prehospital and Disaster Medicine, 32(6), 673-678. https://doi.org/10.1017/S1049023X17006720

World Health Organization [WHO]. (2020). Archived: WHO Timeline-COVID-19. Retrieved June 10, 2021, from https://www.who.int/news/item/27-04-2020-who-timeline---covid-19

Zhou S. J., Zhang, L. G., Wang, L. L., Guo, Z. C., Chen, J. C., ... Chen, J. X. (2020). Prevalence and socio-demographic correlates of psychological health problems in Chinese adolescents during the outbreak of COVID-19. Eur Child Adolesc Psychiatry, 29, 749-758. https://doi.org/10.1007/s00787-020-01541-4

\section{Copyrights}

Copyright for this article is retained by the author(s), with first publication rights granted to the journal.

This is an open-access article distributed under the terms and conditions of the Creative Commons Attribution license (http://creativecommons.org/licenses/by/4.0/). 